DOI: 10.20472/IAC.2019.045.013

\author{
HANNAH DUNGA \\ VAAL UNIVERSITY OF TECHNOLOGY, South Africa
}

\title{
A CRITIQUE OF THE CONCEPTUALIZATION OF CHILD POVERTY
}

\begin{abstract}
:
Poverty measures have evolved over the years from the income-based poverty threshold to those that take into account non-income aspects of a person's wellbeing, the popular one being the multidimensional poverty measure. In all these measures children have been taken for granted in terms of the unique nature and the multifaceted deprivations that may be associated with children and not adults. The employment of equivalence scales makes assumptions that go to the extent of looking at children in different contexts and households as being homogenous. A proper measure that takes into account individual idiosyncrasies may not be easy but the current measures that are being applied are to a greater extent underestimating the level of child poverty globally and specifically in developing countries. This paper is motivated by the understanding that there could be more poor children than we care but we are not able to count based on the existing measures of poverty. This paper presents a critique of the child poverty measures that exist and points out the fact that there is need to develop a dedicated and succinct measure of child poverty beyond the equivalence scales that relate child poverty to the household income poverty line.
\end{abstract}

\section{Keywords:}

child poverty, measures, scale, household

JEL Classification: 132 


\subsection{Introduction}

Poverty eradication as a global agenda requires concerted effort from all fronts if there is to be any meaningful strides in the reduction and eradication effort. The Word bank (2018) reports that poverty levels have been reduced substantially in Asia but they are signs of slackness and even indications that poverty levels are increasing in sub-Saharan Africa (The World Bank, 2018). The extent of poverty can only be understood if correct measures are used. Bradshaw (2006) explain that policy interventions are informed by the theories and the view that the policy makers hold about poverty. Similarly, misdiagnosis of what poverty is and the inaccuracy in measurements may lead to policies that will not deal with the problem correctly. Poverty studies (Blank, 2003; House, n.d.; Leatt, 2006; The World Bank, 2018; Ugarte, 2011; UNDP, 2004; World Bank, 2016; Yembilah \& Lamb, 2017; Zick \& Smith, 1991) have identified children, women and the old aged as the most vulnerable groups that need special attention in the fight against poverty. The extent of poverty among these groups may not be clear as most measure that are used in research are generalized for all individuals regardless of gender and age. The critical component in the measure of poverty that needs to be given special attention is child poverty. Although children exist in a household, their circumstances may not be exactly and identical to those of the adults within the household. This paper intends to present a critique of the child poverty measures found in the literature, the paper will attempt to outline the weaknesses in the conceptualization of child poverty and the measures used in the child poverty literature, the paper will also attempt to suggest areas that can be included in the existing measures to strengthen the measurement and hence the understanding of child poverty. The rest of the paper is organized as follows, section 1.2 will present the background to child poverty study in the context of poverty in general by pointing at the main definition of poverty and how children are included or excluded. Section 2 will be a literature review on the concept of poverty and the measures of poverty in general section 3 will present the existing child poverty measures and point out the weaknesses in the measurement, section 4 will the conclusion and recommendation

\subsection{Background to poverty and poverty measures}

The conceptualization of any phenomenon is important in the pursuit of its study and any attempts to measure of quantify is extent. The definition of poverty to some extent determines the measurements to be used therein. For example, the understanding of poverty as a monetary issue led to the introduction on the monetary poverty line whether based on income or consumption (Rio Group, 2006; Meyer \& Sullivan, 2012). The United nations defined poverty as "a denial of choices and opportunities, a violation of human dignity. It means lack of basic capacity to participate effectively in society. It means not having enough to feed and clothe a family, not having a school or clinic to go to, not having the land on which to grow one's food or a job to earn one's living, not having access to credit. It means insecurity, powerlessness and exclusion of individuals, households and 
communities. It means susceptibility to violence, and it often implies living on marginal or fragile environments, without access to clean water or sanitation." This on its own indicate that poverty is beyond money, poverty is multidimensional. However the multidimensional nature of poverty is not a new thing, it has been recognized in the literature, (Alkire \& Foster, 2013; Alkire \& Housseini, 2014; The World Bank, 2018; Unicef, 2011) However, whilst accepting the multidimensional nature of poverty, there has been very little effort to make the measures comply to this realization. The measures of poverty in general have also remained biased to income or expenditure and has generalized the unit of measurement to the extent that the household has become the popular unit of measurement without considering the intra-household distribution. Harold Watts pointed out in his discussion paper titled 'an economic definition of poverty' that the widespread dissatisfaction with antipoverty policies in his time was due to the failure to make an explicit choice of a restrictive definition of poverty (Watts, 1968). He argued that, "in a situation where each critic can choose from a wide range of poverties--and feels no need to restrict his choice to any single one--it is no hard task to find all policies wide of some target" in his argument Watts stresses the need to a have a clear restrictive definition of what poverty is in order to have a much directed policy that yields results. The issue of child poverty suffers from the same problem, what is child poverty? Do the children experience poverty the same way adults do? If no are there different definitions and measures even policies to deal with child poverty outside the broader poverty reduction policies? The understanding of the fact that children face their own set of problems makes it necessary that child poverty be conceptualized separately.

\subsection{Literature review on the conceptualization child poverty}

UNICEF, (2005) eloquently pointed out about child poverty that "Children experience poverty as an environment that is damaging to their mental, physical, emotional and spiritual development. Therefore, expanding the definition of child poverty beyond traditional conceptualizations, such as low household income or low levels of consumption, is particularly important. And yet, child poverty is rarely differentiated from poverty in general and its special dimensions are seldom recognized" The traditional definition of poverty is basically poverty experienced by children (Yembilah \& Lamb, 2017) thus, poverty in the sense of the general understanding but experienced by children. That definition on its own as UNICEF pointed out is faulty in many ways, first, it considered poverty to be generic, and intrinsically based on the adult poverty definition (United Nations Children's Fund (UNICEF), 1998). In the essay on child poverty in South Africa Leatt, (2006) also attempted to define child poverty by arguing that child poverty is "a situation where children do not have enough resources to grow healthy and strong, to get an education, to live in a good and safe environment, and to fulfil their potential. Where children are deprived of the resources needed to grow and develop, they are living in poverty" This was an attempt to include as much as possible within a single definition, however to even half of what needs to be captured would be represented in this very good attempt. The fact that poverty in 
general has evolved so much within the last three decades with the development of a multidimensional measure of poverty in less than a decade ago, is a clear indication that if child poverty is to be considered as a sub-set of poverty then its definitions were also just being developed within the same period howbeit at a much slower pace.

Yembilah and Lamb, (2017) in their report acknowledged that there is no widely accepted definition of child poverty. This does not mean that nobody attempted to define child poverty, it is just an assertion that whatever definitions exist, they are not through a universally agreed process. Ibid pointed out that the absence of a definition was true for Calgary of Alberta Canada, but that may not be true of many parts of the world. Also Briggs and Lee's (2012) in their research for Vibrant Communities Calgary also agreed with the absence of a consensus around a definition of child poverty (Yembilah \& Lamb, 2017). Now the fact that a definition that is widely agreed upon does not exist, how can a measure exist? Those that have attempted to measure poverty, what was their operating definition? Yembilah and Lamb (2017) went on to point out that "The inherent risk in separating child poverty into lack of money and the impacts of lack of money could lead to policies and practices around child poverty that are superficial" Thus meaning that policies that are based on a wrong concept of what child poverty is are bound to fail. The importance of looking at child poverty with a different focus is that child poverty is not only poverty of today, but of tomorrow if not dealt with. Also because children in poverty are victims of their birth, they have no say no ability to control the household in which they are born (UNDP, 2004).

\subsection{Conclusion and recommendation}

The paper critiqued the conceptualization of existing child poverty measures. While the paper recognized the fact that poverty is regarded multidimensional in nature, there has been very little effort to make the measures comply to this realization. The measures of poverty in general have remained biased to income or expenditure and has generalized the unit of measurement to the extent that the household has become the popular unit of measurement without considering the intra-household distribution. The paper has argued that regarding the problems on concepts of child poverty, they do not emerge from its measurements only but rather form the definition of what is meant by child poverty. The paper further showed the gaps in literature in terms of how child poverty has been defined and later measured. It was noted that most studies generalized the picture of child poverty when, yet this problem should be categorized according to geographical settings. It is evident that what may be regarded as child poverty in developing countries may not be the same as in developed countries.

The other point argued in the paper is the on the measures of poverty at household level where children are incorporated into the household poverty line. It should be noted that children have different needs as compared to adults hence if child poverty is not considered separately, children may be taken for granted in terms of the unique nature and the 
multifaceted deprivations that may be associated with them. This paper concluded that based on the current child poverty measures, there could be more poor children than we care but we are not able to count them based on the existing measures of poverty. Hence it is suggested that there is need to develop a dedicated and succinct measure of child poverty beyond the equivalence scales that relate child poverty to the household income poverty line.

\section{$4 \quad$ References}

Alkire, S., \& Foster, J. E. (2013). A Report on Mexican Multidimensional Poverty Measurement (No. 60). Oxford.

Alkire, S., \& Housseini, B. (2014). Multidimensional Poverty in Sub-Saharan Africa : Levels and Trends (MD Poverty in Africa No. 81). OPHI.

Blank, R. M. (2003). Selecting Among Anti-Poverty Policies: Can an Economist be Both Critical and Caring? Review of Social Economy, 61(4), 447-469. https://doi.org/10.1080/0034676032000160949

Group, R. (2006). Introduction: compendium of best practices in poverty measurement. In Compendium of Best Practices in Poverty Measurement (pp. 15-34).

House, C. R. (n.d.). Poverty's Cause and Effect, New World Outlook 100 Year Review.

Leatt, A. (2006). Child poverty: Its meaning and extent. South African Child Gauge 2006, 19-23.

Meyer, B. D., \& Sullivan, J. X. (2012). Identifying the Disadvantaged: Official Poverty, Consumption Poverty, and the New Supplemental Poverty Measure. Journal of Economic Perspectives, 26(3), 111-136. https://doi.org/10.1257/jep.26.3.111

The World Bank. (2018). Poverty and Shared Prosperity 2018: Piecing together the poverty puzzle. https://doi.org/10.1596/978-1-4648-0958-3

Ugarte, C. (2011). The effect of growth on poverty reduction Jaya Krishnakumar, (June).

UNDP. (2004). Children and poverty. In Focus.

Unicef. (2011). UNICEF POLICY AND PRACTICE A Multidimensional Approach to Measuring Child Poverty, (February).

United Nations Children's Fund (UNICEF). (1998). The State of the World's Children 2205; Childhood Under threat.

Watts, H. W. (1968). AN ECONOMIC DEFINITION OF POVERTY. MADISON, WINSICONSIN.

World Bank. (2016). Poverty and Shared Prosperity 2016: Taking on Inequality. https://doi.org/10.1596/9781-4648-0958-3

Yembilah, R., \& Lamb, C. (2017). Rights, Capabilities and Obligations : New Perspectives on Child Poverty in Calgary Final Report of the Multidimensional Defi nition of Child Poverty Project. Calgary, Alberta.

Zick, C. D., \& Smith, K. R. (1991). Marital Transitions, Poverty, and Gender Differences in Mortality. Journal of Marriage and Family, 53(2), 327-336. https://doi.org/10.2307/352902 